\title{
ANÁLISE DOS RESÍDUOS SÓLIDOS E ALTERNATIVAS PARA MINIMIZAR SEUS EFEITOS EM UMA UNIDADE DE ENSINO DE JOVENS E ADULTOS DO RIO DE JANEIRO
}

\author{
Antonio Carlos do Prado Ribeiro \\ Graduando em Ciências Biológicas - Universidade do Estado do Rio de Janeiro \\ UERJ / CECIERJ / CEDERJ \\ $\triangle$ prado76bio@gmail.com \\ Elizabeth dos Santos Rios \\ Mestre em Botânica - Professora Assistente da Universidade do Estado do Rio de Janeiro \\ DECOL / IBRAG / UERJ - RJ - Brasil
}

\section{Resumo:}

O crescimento desordenado das cidades gerou problemas para a sociedade humana devido ao desconhecimento dos impactos que seriam causados ao meio ambiente. A utilização sem controle de matéria-prima e energia compromete diversos ecossistemas e ocasiona poluição em escala global que pode afetar as gerações futuras e as diferentes formas de vida. $\mathrm{O}$ presente trabalho foi desenvolvido em uma Unidade Educacional de jovens e adultos do Ensino Médio e teve como objetivo reforçar a importância da preservação do meio ambiente através do gerenciamento e destinação adequada dos resíduos sólidos produzidos no Colégio. O cotidiano escolar com relação à gestão dos resíduos sólidos foi observado em um período total de dezesseis dias, onde os resíduos segregados foram analisados e pesados. Os dados obtidos foram agrupados em tabelas e gráficos, contribuindo para a elaboração de propostas alternativas e atividades em Educação Ambiental, de modo a minimizar os efeitos dos resíduos sólidos no ambiente escolar e na comunidade.

Palavras-chave: Educação Ambiental. Meio Ambiente. Resíduos Sólidos

\section{ANALYSIS OF SOLID WASTE AND ALTERNATIVES TO MINIMIZE ITS EFFECT ON A YOUNG TEACHING OF UNITY AND RIO DE JANEIRO ADULTS}

\begin{abstract}
:
The unplanned growth of cities has caused problems for human society due to ignorance of the impacts that would be caused to the environment. The uncontrolled use of raw materials and energy undertakes various ecosystems and causes pollution on a global scale that can affect future generations and different ways of life. This study was conducted in an Educational Unit and young adults of high school and aimed to reinforce the importance of preserving the environment through the management and proper disposal of solid waste produced in high school. The school routine with respect to solid waste management was observed in a total of sixteen days, where the segregated waste were analyzed and weighed.
\end{abstract}


Data were grouped in tables and graphs, contributing to the development of alternatives and activities in environmental education proposals, in order to minimize the effects of solid waste in the school environment and community.

Keywords: Environmental Education. Environment. Solid Waste.

\title{
ANÁLISIS DE RESIDUOS SÓLIDOS Y ALTERNATIVAS PARA MINIMIZAR SU EFECTO EN UMA ENSEÑANZA JOVEN DY UNIDA DY RIO DE JANEIRO ADULTOS
}

\begin{abstract}
Resumen
El crecimiento no planificado de las ciudades há causado problemas a la sociedad humana debido a la ignorância de los impactos que se causen al medio ambiente. El uso incontrolado delas materias primas y la energia se compromete diversos ecosistemas y causa contaminación a escala global que puede afectar a las futuras generaciones y diferentes formas de vida. Este estudio se realizó em una Unidad Educativa y adultos jóvenes de la escuela secundaria y dirigido a reforzar la importancia de preservar el medio ambiente per la gestión y la disposición adecuada de los resíduos sólidos producidos en la escuela secundaria. La rutina de la escuela con respecto a la gestión de residuos sólidos se observó en un total de dieciséis días, donde se analizaron y se pesan los resíduos segregados. Los datos se agrupan en tablas y gráficos, lo que contribuye al desarrollo de alternativas y actividades en las propuestas de Educación Ambiental, con el fin de minimizar los efectos de los residuos sólidos en el entorno escolary comunitario.
\end{abstract}

Palabras clave: Educación Ambiental. Medio Ambiente. Residuos Sólidos

\section{INTRODUÇÃO}

Os resíduos sólidos acompanham a espécie humana desde a pré-história. Tornaram-se um problema a partir do momento em que a humanidade começou a se organizar em comunidades. O acúmulo de dejetos passou a perturbar a qualidade de vida da sociedade devido ao fato de provocar mau cheiro e atrair organismos transmissores de doenças. Durante a Idade Média, as cidades haviam se desenvolvido bastante, mas ainda não existia a preocupação com as questões sanitárias e ambientais. Os resíduos sólidos e líquidos se acumulavam ao longo das áreas urbanas e contribuíam para a proliferação de organismos causadores de doenças. Nesse período uma grande epidemia de peste negra, causada por uma bactéria transmitida por picadas de pulgas presentes nos ratos, dizimou grande parte da população européia. Com o advento da Revolução Industrial, a partir do século XVIII, a demanda por trabalhadores nas fábricas provocou um grande deslocamento da população rural para as cidades. Formaram-se enormes aglomerações urbanas, cuja infraestrutura, principalmente sanitária, não estava preparada para tal crescimento populacional. Além disso, 
o extraordinário aumento na população de bens de consumo acarretou no não menos exorbitante aumento na geração e descarte de diferentes tipos de resíduos. (EIGENHEER, 2009)

Freitas et al. (2011) explica que no século XXI, tudo está relacionado à compra de bens e serviços e podemos verificar um grande crescimento do consumo de produtos supérfluos, embora esse termo possa ser dúbio, porque o valor de uso tem sido dado por julgamentos individuais e subjetivos. Produtos supérfluos seriam aqueles que de fato não têm utilidade prática ou mesmo que tenham, vão muito além da necessidade em termos de preços ou funções. Seu valor é dado pela marcação de status, pela flexibilidade da moda e dos meios de comunicação.

Segundo a Política Nacional de Resíduos Sólidos (PNRS), Lei n 12.305 que institui a Política Nacional de Resíduos Sólidos, altera a Lei $n^{\circ}$ 9.605, de 12 de fevereiro de 1998 e dá outras providências. (BRASIL, 2010), o resíduo sólido é:

\begin{abstract}
Material, substância, objeto ou bem descartado resultante de atividades humanas em sociedade, a cuja destinação final se procede, se propõe proceder ou está obrigado a proceder, nos estados sólido ou semissólido, bem como gases contidos em recipientes e líquidos cujas particularidades tornem inviável o seu lançamento na rede pública de esgotos ou em corpos d'água, ou exijam para isso soluções técnicas ou economicamente inviáveis em face da melhor tecnologia disponível (BRASIL, 2010, p. 11).
\end{abstract}

Com relação ao rejeito, nessa mesma Lei é definido como "resíduo sólido que, depois de esgotadas todas as possibilidades de tratamento e recuperação por processos tecnológicos disponíveis e economicamente viáveis, não apresenta outra possibilidade que não a disposição final ambientalmente adequada" (BRASIL, 2010, p.11).

Segundo a Pesquisa Nacional de Saneamento Básico (PNSB) realizada pelo Instituto Brasileiro de Geografia e Estatística (IBGE), a quantidade de resíduos sólidos domiciliares e/ou públicos coletados todos os dias dos municípios brasileiros é no total de 259.547 toneladas. Desse valor, geração per capita para a população que em 2008 era de 189.612.814 habitantes, é de aproximadamente de $0,73 \mathrm{~kg} / \mathrm{hab} / \mathrm{dia}$ (BRASIL, 2008). As informações extraídas dessa pesquisa mostram que para os resíduos sólidos no Brasil, não há o reaproveitamento ou reciclagem significativa desses resíduos, sendo destinados, na sua maioria, aos aterros sanitários. Apesar da melhora do sistema de destinação de resíduos sólidos urbanos, $17,61 \%$ ainda são destinados aos lixões a céu aberto, sendo este método o mais inadequado, pois pode trazer impactos negativos significantes no ambiente e na 
população, como contaminação dos recursos hídricos, aumento da população de parasitas e patógenos e, propagação de vetores causadores de doenças.

Com relação aos municípios que possuem o serviço de coleta seletiva, conforme a Pesquisa Nacional de Saneamento Básico (PNSB) realizada pelo IBGE, apenas 17,86\% dispõem da segregação dos resíduos sólidos de acordo com os tipos de resíduos (BRASIL, 2008). A segregação é a primeira etapa para reaproveitamento ou reciclagem dos resíduos sólidos e depende tanto do poder público como da sociedade. A deficiência em separar os resíduos sólidos acaba acarretando a deposição dos mesmos em locais inapropriados, o aumento do volume de resíduos a serem transportados e do volume dos aterros sanitários, diminuindo seus tempos de atividades.

De acordo com Agenda Ambiental na Administração Pública (A3P) “estudos apontam que o consumo dos recursos naturais já excede em $30 \%$ a capacidade do planeta se regenerar, se mantivermos o ritmo atual, somado ao crescimento populacional, em torno de 2030 precisaríamos de mais dois planetas para nos manter" (BRASIL, 2009, p. 37). Por esta razão, cabe ao poder público, ao setor empresarial e a sociedade as mudanças de atitudes com a aplicação da política dos 5R`s na sua prioridade “(Repensar, Reduzir, Reaproveitar, Reciclar e Recusar consumir produtos que geram impactos socioambientais significativos)" (BRASIL, 2009) com a finalidade de utilizar os recursos atuais sem comprometer as gerações futuras.

Este trabalho contribui para a mudança de hábitos em uma unidade formal de ensino, minimizando os impactos sobre o ambiente causado pela poluição decorrente do descarte inadequado de resíduos sólidos, e, estimulando a formação de agentes multiplicadores com atitudes adequadas na utilização dos recursos ambientais.

\section{METODOLOGIA}

O trabalho foi realizado num Colégio localizado no bairro da Ilha do Governador, Rio de Janeiro/RJ. As visitas ocorreram de segunda à sexta-feira, para observação do cotidiano escolar.

As instalações da Unidade de Ensino pertencem à Prefeitura da Cidade do Rio de Janeiro e conta com onze salas de aula, um refeitório, uma quadra poliesportiva, uma secretaria, uma biblioteca, um laboratório de informática, um teatro, uma área que 
corresponde ao pátio e a casa do zelador. No período diurno, atende aos alunos do Ensino Fundamental e é compartilhada pelo Governo do Estado do Rio de Janeiro para atender jovens e adultos do Ensino Regular Médio, no período noturno.

As coletas foram feitas, segundo o Manual de Gerenciamento Integrado de Resíduos Sólidos (MONTEIRO, 2001), de segunda à quinta-feira, no período noturno. O volume dos resíduos coletados sem compactação aconteceu em quatro semanas, durante a paralisação de professores e sem a paralisação, totalizando dezesseis dias. As observações aconteceram no mês de setembro (de 16 a 19 e 23 a 27) e novembro (18, 19, 21 e 25 a 28) do ano de 2013. O gerenciamento de resíduos foi acompanhado desde o recolhimento, acondicionamento, tratamento e destinação final dos mesmos.

Para a pesagem, utilizou-se uma balança de mola portátil pequena, marca Jinding, com capacidade máxima de 11 libras (5 kg), escala de $0,1 \mathrm{~kg}$. Os resíduos foram recolhidos da sala dos professores, cozinha/refeitório, salas de aula e secretaria. A aferição dos pesos após separação do montante dos resíduos sólidos de cada componente (papel, plástico, vidro, metal, orgânico e não reciclável) em cada dependência foi feita sem compactação. Os dados deste procedimento possibilitaram a realização do cálculo diário e semanal da produção de resíduos sólidos em quilogramas $(\mathrm{kg})$, com 1 casa decimal.

A consulta bibliográfica atualizou os conhecimentos sobre os resíduos sólidos e a situação atual do gerenciamento dos mesmos no Município do Rio de Janeiro com relação à coleta seletiva, centros de triagem e aterros sanitários. O bairro da Ilha do Governador é atendido pela Companhia Municipal de Limpeza Urbana (COMLURB, 2013) com a coleta seletiva, oferecendo uma grande vantagem à comunidade escolar.

\section{RESULTADOS}

Os coletores do Colégio estão distribuídos nas diversas instalações, de acordo com a circulação e a permanência temporária de pessoas nas diversas dependências. Todos os resíduos depositados nos coletores são retirados pelos funcionários que os acondicionam em sacos de lixo e os estocam nos contêineres de 240 e 360 litros, colocados na área externa, próximos ao portão dos fundos. Como a mesma instalação é usada pelos docentes, discentes e funcionários da rede regular de ensino do Município e do Estado, esses contêineres armazenam os resíduos gerados no período diurno e noturno. Mesmo não havendo a 
separação dos resíduos gerados, a COMLURB recolhe o conteúdo dos contêineres todas segundas, quartas e sextas-feiras da semana, dando destino final destes resíduos em aterros sanitários e usina de triagem.

\section{Práticas adotadas na Unidade Educacional para minimizar os possíveis impactos dos resíduos sólidos}

O Colégio adotou a prática de cada aluno trazer sua própria garrafa de água, podendo enchê-la no bebedouro do refeitório, reduzindo o descarte de copos descartáveis.

Anualmente, é organizada no $2^{\circ}$ semestre, a "Semana da Sustentabilidade e do Meio Ambiente", com o objetivo de sensibilizar a comunidade escolar sobre este tema no seu cotidiano. Nesta atividade, os alunos das diversas turmas e os professores participaram. Os alunos atuaram ativamente na preparação dos seus temas, pesquisando, debatendo, organizando os materiais necessários e culminando na apresentação dos trabalhos, ocorrendo à integração do Colégio com as diversas áreas de conhecimento.

\section{Observação da Unidade Educacional}

As observações aconteceram nas semanas descritas na Tabela 1. No mês de setembro, o Colégio estava com um público menor do que atende normalmente, devido à paralisação dos professores que reduziu o quantitativo de docentes e discentes. No mês de novembro com o fim da paralisação, houve o aumento do público interno no Colégio e consequente aumento dos resíduos (Tabela 1). 
Tabela 1 - Grupo de componentes do período de observação nas semanas com e sem paralisação

\begin{tabular}{|c|c|c|c|c|c|c|c|}
\hline \multirow{3}{*}{$\begin{array}{c}\text { Semanas } \\
\text { observadas }\end{array}$} & \multicolumn{7}{|c|}{ Quantidade semanal de resíduos gerados $(\mathrm{kg})$} \\
\hline & \multirow{2}{*}{ Total } & \multicolumn{6}{|c|}{ Grupo de componentes observados } \\
\hline & & papel & plástico & orgânico & metal & vidro & $\begin{array}{c}\text { não } \\
\text { reciclável }\end{array}$ \\
\hline Total & 124,5 & 26,4 & 22,8 & 50,6 & 24,3 & 0,2 & $\mathbf{0 , 2}$ \\
\hline Com paralisação & 50,8 & 10,4 & 8,7 & 22,5 & 9,0 & 0,0 & 0,2 \\
\hline $\begin{array}{l}16 \text { a } 19 \text { de } \\
\text { setembro de } 2013\end{array}$ & 24,2 & 4,8 & 4,9 & 10,2 & 4,2 & 0,0 & 0,1 \\
\hline $\begin{array}{l}23 \text { a } 27 \text { de } \\
\text { setembro de } 2013\end{array}$ & 26,6 & 5,6 & 3,8 & 12,3 & 4,8 & 0,0 & 0,1 \\
\hline Sem paralisação & 73,7 & 16,0 & 14,1 & 28,2 & 15,2 & 0,2 & 0,0 \\
\hline $\begin{array}{l}18,19 \text { e } 21 \text { de } \\
\text { novembro de } 2013\end{array}$ & 37,2 & 8,0 & 7,0 & 14,2 & 7,9 & 0,1 & 0,0 \\
\hline $\begin{array}{l}25 \text { a } 28 \text { de } \\
\text { novembro de } 2013\end{array}$ & 36,5 & 8,0 & 7,1 & 14,0 & 7,3 & 0,1 & 0,0 \\
\hline
\end{tabular}

Com relação à composição mais comum dos resíduos sólidos observados no Colégio, estes ficaram bem próximos aos dados de Monteiro (2001) em relação ao Brasil (Tabela 2).

Resíduos eventuais os quais fazem parte do cotidiano ocorreram no Colégio por desuso, fim de funcionamento e limite de utilização; ou gerados com a aquisição de novos produtos. Devido a este fato, foi realizado o levantamento dos possíveis materiais que poderão resultar em resíduos, como as lâmpadas eletrônicas, resíduos de óleo de cozinha, borrachas, pilhas, baterias, celulares inservíveis, equipamentos eletrônicos, panos e trapos, madeiras e entulhos de obras.

Os componentes eventuais com alto grau de periculosidade que podem contaminar o ambiente por metais pesados, como pilhas, baterias e lâmpadas eletrônicas, devem ter um tratamento meticuloso de coleta, acondicionamento e descarte adequado. Outros podem contaminar recursos hídricos se descartados inadequadamente, e neste caso, o óleo de cozinha que com 1 litro pode contaminar 1 milhão de litros de água, além dos entulhos de obras que podem destruir manguezais. (RABELO, 2008). 
O material orgânico é o resíduo mais gerado devido ao preparo, nos dias de aula, da alimentação (Gráfico 1). Os resultados obtidos ratificam que em países menos desenvolvidos a geração de material orgânico é mais comum do que nos países desenvolvidos, tendo em vista o grande consumo de alimentos semipreparados que produzem resíduos inorgânicos provenientes das embalagens.

Gráfico 1 - Composição mais Comum dos Resíduos Sólidos do Colégio (\%)

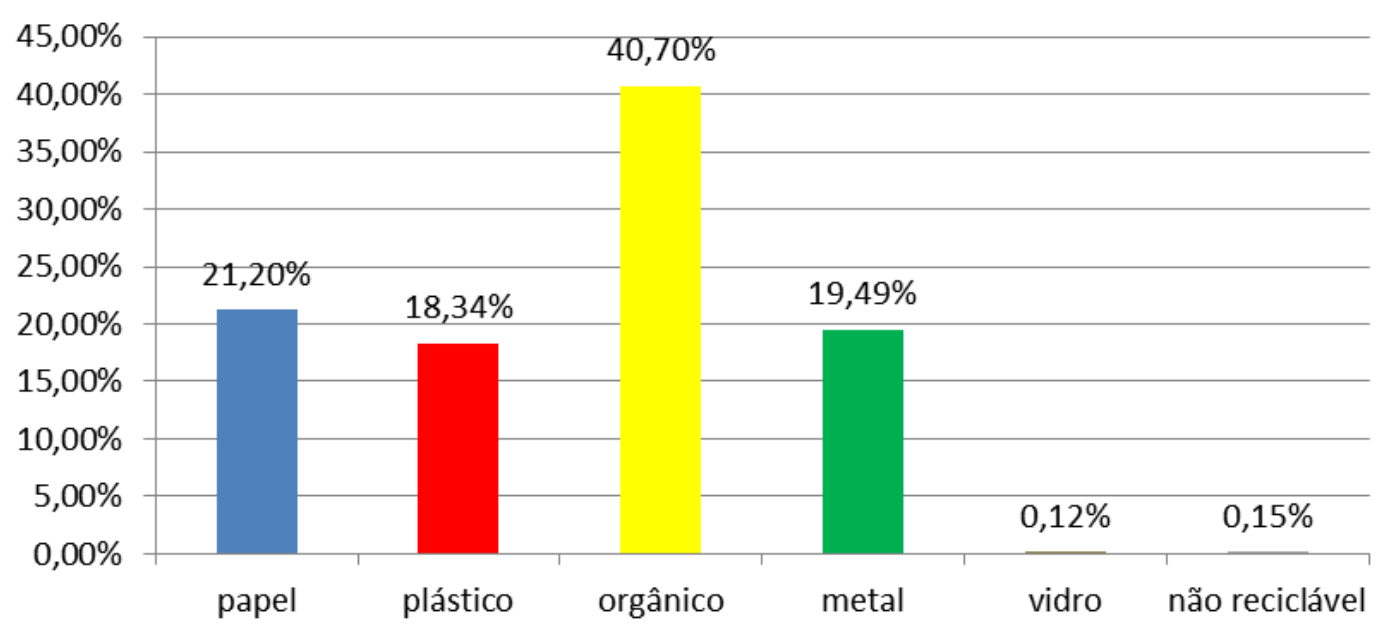

Tabela 2 - Composição mais comum dos resíduos sólidos de alguns países (\%)

\begin{tabular}{ccccc}
\hline Composto & Brasil & Alemanha & Holanda & EUA \\
\hline Matéria & 65,00 & 61,20 & 50,30 & 35,60 \\
orgânica & 3,00 & 10,40 & 14,50 & 8,20 \\
Vidro & 4,00 & 3,80 & 6,70 & 8,70 \\
Metal & 3,00 & 5,80 & 6,00 & 6,50 \\
Plástico & 25,00 & 18,80 & 22,50 & 41,00 \\
Papel & &
\end{tabular}

Fonte: MONTEIRO et al., 2001.

Comparando a Tabela 3 com a Tabela 4, a média per capita de resíduos se refere ao período de 4 horas de funcionamento do Colégio. Se esta média for mantida em um período de 24 horas, a geração de resíduos fica próxima ao consumo diário de uma cidade de pequeno porte, de até 30 mil habitantes. Isto de fato comprova o alto consumo per capita que acompanha com referência ao crescimento da população urbana e com a disseminação da cultura do consumo, ou seja, a sociedade consumista. 
Tabela 3 - Média (per capita) de resíduos gerados no Colégio (kg/pessoa)

\begin{tabular}{lccc}
\hline \multicolumn{1}{c}{ Semanas observadas } & Total $(\mathrm{kg})$ & Total de pessoas (1) & Média \\
\hline Total de resíduos gerados & $\mathbf{1 2 4 , 4}$ & $\mathbf{1 8 0 2}$ & $\mathbf{0 , 0 7}$ \\
Com paralisação & 50,8 & 662 & 0,08 \\
16 a 19 de setembro de 2013 & 24,2 & 326 & 0,07 \\
23 a 27 de setembro de 2013 & 26,6 & 336 & 0,08 \\
Sem paralisação & 73,6 & 1140 & 0,06 \\
18, 19 e 21 de novembro de 2013 & 37,1 & 548 & 0,07 \\
25 a 28 de novembro de 2013 & 36,5 & 592 & 0,06 \\
\hline
\end{tabular}

(1) os valores numéricos são referentes à soma do público total presente nos dias das observações.

Tabela 4 - Faixas de variação média mais utilizada da geração de resíduos per capita (MONTEIRO et al., 2001)

\begin{tabular}{ccc}
\hline Tamanho da cidade & $\begin{array}{c}\text { População urbana } \\
\text { (habitantes) }\end{array}$ & $\begin{array}{c}\text { Geração per capita } \\
\text { (kg/hab/dia) }\end{array}$ \\
\hline Pequena & - Até 30 mil & 0,50 \\
Média & - De 30 mil a 500 mil & De 0,50 a 0,80 \\
Grande & - De 500 mil a 5 milhões & De 0,80 a 1,00 \\
Megalópole & - Acima de 5 milhões & Acima de 1,00 \\
\hline
\end{tabular}

A dependência do Colégio que mais gerou resíduos foi a cozinha/refeitório, seguida das salas de aula, secretaria e sala de professores (Gráfico 2). A geração de resíduos nas dependências está proporcionalmente relacionada ao atendimento, permanência e trânsito de pessoas, fazendo com que a cozinha/refeitório gerasse mais resíduos devido ao atendimento do público interno no horário das refeições.

Gráfico 2 - Resíduos gerados nas dependências do Colégio (\%)

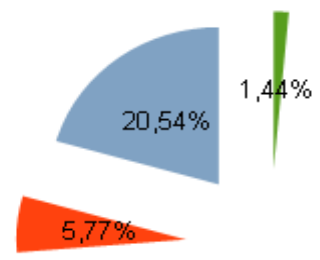




\section{Problemas encontrados na Unidade Educacional}

O colégio, apesar de sua limitação com relação ao planejamento administrativo, de recursos humanos e financeiros, tenta sensibilizar e formar um cidadão mais reflexivo e que pense coletivamente. Porém, um dos problemas encontrados foi o descarte de materiais em locais inapropriados gerando mais trabalho para as equipes de limpeza. Estes locais se tornam menos aconchegantes, podendo abrigar vetores causadores de doenças, além de poluir água e terra, e, entupir galerias de águas pluviais.

Em relação aos coletores, estão bem distribuídos de forma a atender o público interno, porém não há segregação com coletores coloridos, conforme Resolução CONAMA nº 275 , de 25 de abril de 2001 (BRASIL, 2001). Constatou-se também a inexistência de um centro de triagem ou um local coberto na área externa que proteja os resíduos da ação de chuvas e do tempo até o seu recolhimento pela COMLURB. Apesar da cidade do Rio de Janeiro fazer a coleta seletiva, esta recolhe os resíduos de forma limitada, recolhendo os materiais que poderão ser recicláveis separados dos materiais que não poderão ser reciclados e orgânicos. Este tipo de procedimento não exime a responsabilidade de segregação de resíduos e a destinação correta dos mais perigosos, que contenham substâncias tóxicas e/ou potencialidades, de danos à saúde pública e ambiental.

\section{DISCUSSÃO}

A civilização humana, ao longo de sua existência, transformou o planeta com o avanço do conhecimento e da tecnologia. Esse avanço não aconteceu de forma harmoniosa com os recursos finitos disponíveis no planeta e atualmente, esse quadro agravou com o estilo de vida imposto pelo sistema capitalista da cultura do consumismo desenfreado.

Podemos citar como principais fatores que levaram à situação atual: ausência de legislação rígida, crescente industrialização, estabelecimento de um maior consumo pela população, pouca conscientização da sociedade quanto à consequência do gerenciamento inadequado de resíduos, falta de projetos pedagógicos que possam ser desenvolvidos em sala de aula ou fora dela, mudança de hábitos e atitudes a serem trabalhados na Escola e com a comunidade envolvendo informações sobre o cotidiano da população. É importante que se tenha o processo educacional como instrumento de ações aplicadas na "construção do saber", assim como no exercício da cidadania. 
Segundo Freitas et al. (2011), a cognição das pessoas parece girar sempre em torno de como consumir mais e diferente. Assim, o novo já nasce efêmero. Esses consumidores não questionam sequer a real necessidade do produto ou serviço, ou mesmo sabem se não possuem utilidade para o usuário.

A partir dos resultados obtidos foram elaboradas alternativas, para minimizar os impactos na Unidade Educacional:

\section{Continuação anual da "Semana da Sustentabilidade e do Meio Ambiente"}

O evento ocorreu no período de 26 e 27 de setembro de 2013, apresentando resultados positivos, e sendo relevante, deve ser mantido. As oficinas do ano de 2013 abordando temas como a reciclagem, saneamento básico, lixo, reaproveitamento de material orgânico (restos de cascas de frutas e legumes), os 5R`s (reduzir, repensar, reaproveitar, reciclar e recusar, ou seja, consumir produtos que gerem impactos socioambientais significativos) devem ser mantidas.

Outras atividades como palestras e exposições para disseminar o conhecimento sobre o assunto são boas opções para motivação do público interno. A participação da comunidade local neste processo é muito importante, pois é nela que o Colégio está inserido e onde são formados cidadãos reflexivos e atuantes na sociedade.

\section{Fortalecer o tema "Sociedade do Consumo e suas consequências" nas aulas de Educação Ambiental}

A Educação Ambiental no Brasil foi instituída pela Lei 9.795, de 27 de abril de 1999 que dispõe sobre a educação ambiental, institui a Política Nacional de Educação Ambiental e dá outras providências (BRASIL, 1999). Segundo Lopes (2011) a Educação Ambiental:

Transpõe os limites das Ciências Naturais, caminhando entre as diversas áreas do conhecimento humano e envolve os processos por meio dos quais indivíduos e a coletividade constroem valores sociais, conhecimentos, habilidades, atitudes e competências voltadas para a conservação do meio ambiente, bem de uso comum da sociedade, essencial à sadia qualidade de vida e sua sustentabilidade. (LOPES, 2011, p.61).

Segundo os Parâmetros Curriculares Nacionais para o Ensino Médio (BRASIL, 2000), a poluição ambiental, seja ela urbana ou rural, do solo, das águas ou do ar, não é algo só biológico, físico ou químico, pois o ambiente, poluído ou não, cabe nas fronteiras de qualquer disciplina, exigindo, não somente das Ciências da Natureza, mas também das Ciências 
Humanas, se pretenderem que a problemática efetivamente socioambiental possa ser mais adequadamente equacionada, num exemplo da interdisciplinaridade imposta pela temática real.

A sociedade do consumo não causa somente o problema da geração de resíduos, mas outros graves como o aumento do consumo de energia, matéria-prima, água, degradação do ambiente, destruição de ecossistemas, contaminação do ar, solo e água e desigualdades sociais. A Educação Ambiental neste sentido visa a reflexão dos alunos e funcionários a uma vida consumista com comprometimento ambiental, ao contrário do que aprendemos nos meios de comunicação, onde podemos consumir mais e reciclar mais.

\section{Implantação da Agenda 21 escolar}

De acordo com Cadei (2011), a Agenda 21 é um plano de ação para o século XXI que visa à sustentabilidade da vida na Terra. Trata-se de uma carta de compromissos com o meio ambiente, constituindo em uma estratégia de sobrevivência da humanidade. Deve agir diretamente com os diretores, alunos e funcionários para priorizar os problemas que afetem a qualidade de vida na comunidade em torno da escola e propor soluções. Este caminho deve ser compartilhado entre a comunidade local, comunidade vizinha, parceiros e o poder público para a construção de um plano de ação que vise melhorar as condições do Colégio e da comunidade. O processo de implantação da Agenda 21 escolar abrange as seguintes etapas: sensibilização, capacitação e formação da comunidade escolar para o projeto, a realização de um diagnóstico socioambiental local (do Colégio e/ou entorno do mesmo) e o plano de ação para a resolução dos problemas, além da avaliação, retroalimentação e abertura de canais de participação.

\section{Proposta de Gerenciamento de Resíduos Sólidos da Unidade Escolar}

De acordo com a Política Nacional dos Resíduos Sólidos (BRASIL, 2010), as pessoas físicas ou jurídicas são responsáveis pela implementação e operacionalização integral do plano de gerenciamento de resíduos sólidos. O Plano de Gerenciamento de Resíduos Sólidos é um instrumento que operacionaliza procedimentos de deposição correta dos resíduos gerados, coleta, acondicionamento e destinação adequados.

A proposta atuaria como norteador do Colégio com relação aos possíveis impactos que os resíduos sólidos possam provocar à saúde pública e ao meio ambiente, visando também o cumprimento de metas para redução dos resíduos gerados, parcerias com outras instituições 
públicas ou privadas para destinação ambientalmente correta dos resíduos, gerando emprego, reaproveitamento de materiais e reciclagem.

\section{CONSIDERAÇÕES FINAIS}

Mudanças em nosso padrão de vida deveriam atender ao slogan da Agenda 21: pense globalmente, aja localmente. Somos responsáveis ambientais da atualidade e não podemos ignorar os impactos negativos que causamos ou achar que este é um problema somente dos governantes. Atitudes simples como reduzir o consumo, trocar ou doar materiais entre parentes e amigos, e, adquirir o que realmente precisar sem exageros é um bom começo. Destinar os resíduos corretamente aos serviços de limpeza urbana, reaproveitar materiais e disseminar o conhecimento de um consumo ambientalmente correto pode fazer a diferença para o futuro.

Como a degradação do ambiente e dos ecossistemas está diretamente ligada ao consumo da sociedade, o poder público, as instituições privadas e a própria sociedade devem agir coletivamente interagindo na busca de soluções. As instituições de ensino público ou privado têm um papel de relevância neste processo, pois é na Escola que são formados os cidadãos, local em que alunos e comunidade têm a oportunidade de conhecer e refletir sobre seus problemas, à busca de soluções e ao direito à cidadania.

Neste trabalho observamos o cotidiano do ambiente escolar com relação ao seu consumo, deposição, acondicionamento e destinação de resíduos, além de práticas de sensibilização voltadas à sustentabilidade. Apesar do Colégio não possuir um plano de gerenciamento de resíduos, este adota medidas para a destinação dos mesmos.

A implantação de ações para preservação ambiental que minimizem os impactos dos resíduos sólidos no ambiente escolar e em seu entorno, conduzem a uma reflexão sobre a necessidade de se alterar a forma de consumo, através de novos hábitos e atitudes, princípios da Educação Ambiental. 


\section{REFERÊNCIAS BIBLIOGRÁFICAS}

BRASIL. Lei 9.795, de 27 de abril de 1999 -Dispõe sobre a educação ambiental, institui a Política Nacional de Educação Ambiental e dá outras providências. Diário Oficial da República Federativa do Brasil, Poder Legislativo, Brasília, DF, Edição 79, 28 abr. 1999. Seção 1, p. 41.

BRASIL. Secretaria de Educação Média e Tecnológica. Parâmetros Curriculares Nacionais para o Ensino Médio. Brasília, DF: MEC/SEMTEC, 2000. 58p. Disponível em: <http://portal.mec.gov.br/seb/arquivos/pdf/blegais.pdf>. Acesso em: 29 jun. 2015.

BRASIL. Resolução CONAMA no 275, de 25 de abril de 2001. Diário Oficial da República Federativa do Brasil, Brasília, DF, 117-E, 19jun. 2001, Seção 1, p. 80.

BRASIL. Instituto Brasileiro de Geografia e Estatística - IBGE. Pesquisa Nacional de Saneamento Básico 2008. Disponível em:< http://www.ibge.gov.br/home/estatistica/populacao/condicaodevida/pnsb2008/defaulttabpdf man_res_sol.shtm>. Acesso em 29 jan. 2014.

BRASIL. Ministério do Meio Ambiente - MMA. Agenda Ambiental na Administração Pública - A3P - 5 Ed. Brasília, DF, 2009. 100 p.

BRASIL. Presidência da República. Lei 12.305, de 2 de agosto de 2010 - Política Nacional dos Resíduos Sólidos - 2. Ed. Brasília, DF: Câmara dos Deputados, Edições Câmara, 2012. 73 p. - (Série Legislação; n. 81).

BRASIL. Companhia Municipal de Limpeza Urbana - COMLURB. Bairros com coleta seletiva no município do Rio de Janeiro. Rio de Janeiro, RJ: Prefeitura da Cidade do Rio de Janeiro, 2013. Disponível em:< http://www.rio.rj.gov.br/web/comlurb/exibeconteudo?id=4380174>. Acesso em: 26 mar. 2014.

CADEI, Marilene de Sá (Org). Educação Ambiental e Agenda 21 escolar; formando elos de cidadania: livro do professor. 2.ed. Rio de Janeiro: Fundação CECIERJ, 2011. 312 p.

EIGENHEER, Emílio Maciel. A História do Lixo, a limpeza Urbana Através dos Tempos. Porto Alegre: Palloti, 2009, 144p.

FREITAS, Ricardo Ferreira; OLIVEIRA, Janete da Silva (Org), PEREIRA, Layne do Amaral, PERET, Luiz Eduardo Neves, SOUSA, Mônica, PIZA, Rafael Nacif de Toledo, FORTUNA, Vania Oliveira. Olhares Urbanos: estudos sobre a metrópole comunicacional. São Paulo: Summus. 2011. 158.p.

LOPES, Alexandre Ferreira, FERREIRA, Déia Maria; SANTOS, Laísa Maria Freire dos. Educação Ambiental v.1. Rio de Janeiro: Fundação CECIERJ, 2011. 208 p.

LOPES, Alexandre Ferreira, FERREIRA, Déia Maria, SILVA, Fábio Alves Leite da, SANTOS, Laísa Maria Freire dos. Educação Ambiental. v.2. 2.ed. Rio de Janeiro: Fundação CECIERJ, 2011. 206 p. 
MONTEIRO, José Henrique Penido; ZVEIBIL, Victor Zular . Manual Gerenciamento Integrado. Rio de Janeiro: IBAM, 2001, 200p. Disponível em: $<$ http://www.resol.com.br/cartilha4/manual.pdf>. Acesso em: 29 jun. 2015.

RABELO, Aparecida; FERREIRA MENDES, Osmar. Coleta Seletiva de Óleo Residual de Fritura para Aproveitamento Industrial. 2008. Disponível em: $<$ http://www.ucg.br/ucg/prope/cpgss/ArquivosUpload/36/file/Continua/COLETA\%20SELET IVA\%20DE\%20\%C3\%93LEO\%20RESIDUAL\%20DE\%20FRITURA\%20PARA\%20AP\%E 2\%80\%A6.pdf>. Acesso em: 14 mar. 2014. 